\author{
$4^{\text {th }}$ International Symposium on Flood Defence: \\ Managing Flood Risk, Reliability and Vulnerability \\ Toronto, Ontario, Canada, May 6-8, 2008
}

\title{
MAPPING HURRICANE RITA INLAND STORM TIDE
}

\author{
Charles Berenbrock ${ }^{1}$, Robert R Mason, Jr. ${ }^{1}$, and Stephen F Blanchard ${ }^{1}$ \\ 1. U.S. Geological Survey, Reston, VA
}

\begin{abstract}
Flood-inundation data are most useful for decision makers when presented in the context of maps of effected communities and (or) areas. But because the data are scarce and rarely cover the full extent of the flooding, interpolation and extrapolation of the information are needed. Many geographic information systems (GIS) provide various interpolation tools, but these tools often ignore the effects of the topographic and hydraulic features that influence flooding. A barrier mapping method was developed to improve maps of storm tide produced by Hurricane Rita. Maps were developed for the maximum storm tide and at 3-hour intervals from midnight (0000 hour) through noon (1200 hour) on September 24, 2005. The improved maps depict storm-tide elevations and the extent of flooding. The extent of storm-tide inundation from the improved maximum storm-tide map was compared to the extent of flood-inundation from a map prepared by the Federal Emergency Management Agency (FEMA). The boundaries from these two maps generally compared quite well especially along the Calcasieu River. Also a cross-section profile that parallels the Louisiana coast was developed from the maximum storm-tide map and included FEMA high-water marks.
\end{abstract}

Key Words: storm tide, interpolation, water level, barriers, hurricane

\section{INTRODUCTION}

Storm surge refers to a body of elevated water, often described as a dome, resulting from the low barometric pressure and strong circulating winds of a hurricane. As the hurricane makes landfall, so does this dome. More importantly, the hurricane winds also drive ashore waters adjacent and rightward of the hurricane, resulting in storm-tide levels that exceed normal elevations by several feet, even tens of feet. Technically, storm surge refers to the water elevated above the prevailing astronomical tides. The storm tide refers to the total height of the surge plus the astronomical tide and is the effective elevation of maximum flooding.

Historically, hurricane-induced inland storm tide was documented through analysis of structural or vegetative damage and high-water marks (HWMs). However, these sources rarely provided quantitative information about the timing of the flooding, the sequencing of multiple paths by which the storm tide arrived, or the magnitude and duration of waves and wave run-up. In addition, HWMs may be difficult to properly identify and accurately survey and storm-tide elevations determined from them may vary greatly. In response to these deficiencies, the U.S. Geological Survey (USGS) developed and deployed an experimental mobile storm-tide network to provide detailed time-series data for selected hurricane 
landfalls. The network was first deployed to monitor the landfall of Hurricane Rita in southwest Louisiana in September 2005.

As Hurricane Rita approached the coasts of southwest Louisiana and southeast Texas, USGS crews deployed 47 water-level (unvented) and barometric sensors within the projected area of impact. Thirtyfour sensors were positioned to record water levels (generally to within 0.05 foot) and 13 to record barometric pressure. These sensors were located along and near the coast, and concentrated from Sabine Pass, TX, to Abbeville, LA, and at inland distances ranging from a few hundred feet from the coast to approximately 30 miles inland (fig. 1). The sensors were encased in 1.25 -inch metal pipes for protection and strapped to piers, power poles, etc. They recorded data every 30 seconds during Hurricane Rita and for several days afterward as flood waters receded. The sensor deployment and resulting data are described by McGee and others (2006a) and are available through the World Wide Web at http://pubs.usgs.gov/ds/2006/220/.

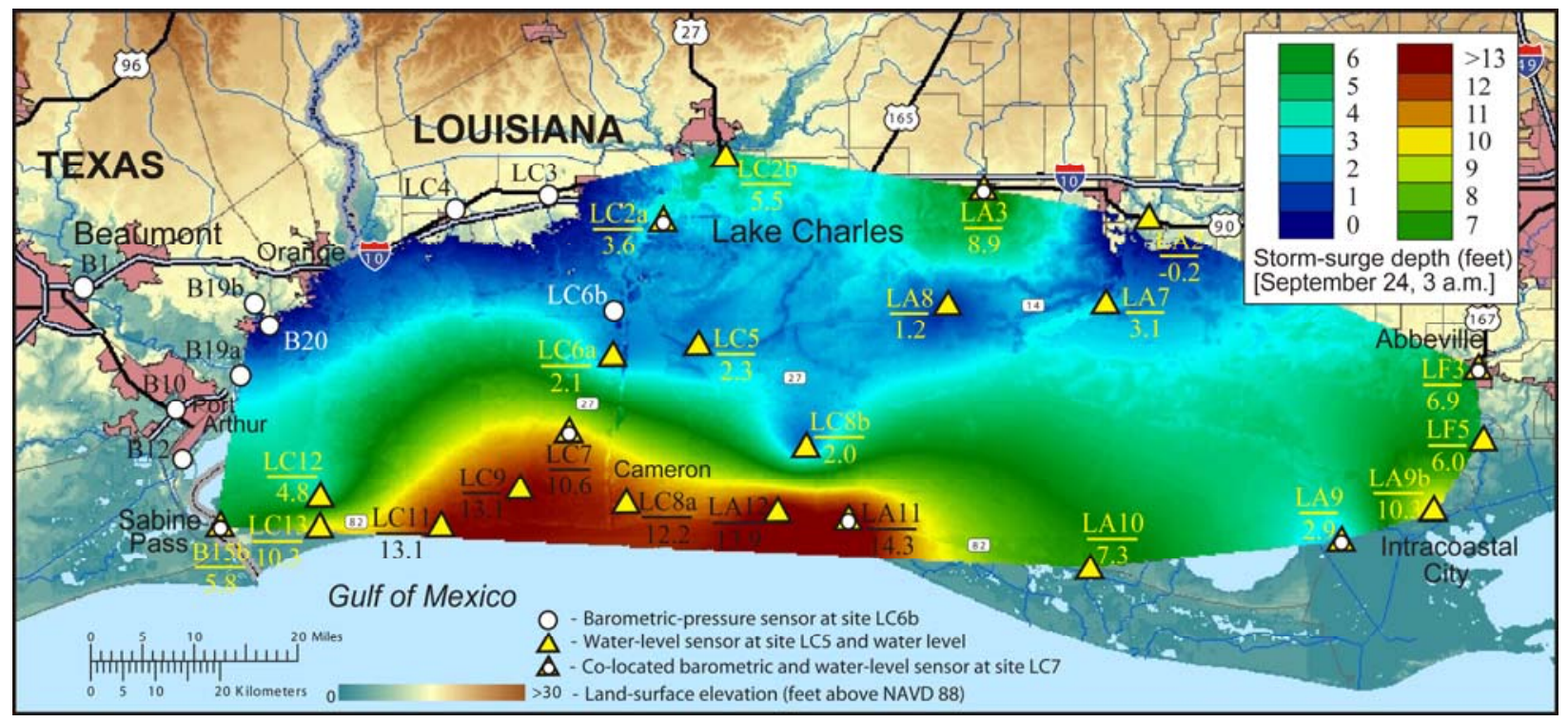

Figure 1. Fitted storm tide at 0300 hours on September 24, 2005, using a spline interpolation. (Modified from figure 8 of McGee and others, 2006b)

Flood-inundation data are most useful for decision makers when presented in the context of maps of effected communities and other areas. But due to the relative scarcity of on-site data, mapping interpolation methods are used to estimate storm tide throughout the flooded area. McGee and others (2006b) used a spline interpolation method to map storm tide at 0300 hours on September 24, 2005, using water-level data collected by the USGS network. But the map is far from perfect, largely ignoring the effects of topography, roads, and other hydraulic features that resist inland flowing waters and is subject to erroneous extrapolations beyond the data locations. For example, the map indicated extensive inundation as far north as Interstate-10 and also in upland areas where land-surface elevations are higher than the recorded water levels for 0300 hours, and thus, these areas were never actually flooded by the storm tide of Hurricane Rita. The surface also shows a large rise east of Lake Charles near sensor LA3 that is unrealistic. The surface in figure 1 was arbitrarily bounded between the sensors. Clearly, simply interpolating a surface from the data may not result in reliable maps.

Many interpolation methods permit depictions of floods, but they often ignore the effects of topographic and hydraulic features that influence the relative depths and extent of flooding. The purpose of this paper is to describe the barrier mapping method and how it was used to produce an improved map of the storm 
tide produced by Hurricane Rita and to compare the improved map to a flood-inundation map prepared by the Federal Emergency Management Agency (FEMA).

\section{THE "BARRIER" MAPPING METHOD}

Creating a map of storm-tide inundation is, at best, an iterative process, often involving approximate steps, refinement, extrapolation, and more refinement. The steps are necessary because interpolation methods and geographic information system (GIS) software cannot automatically evaluate topographic and hydraulic influences from the storm tide. But new algorithms permit the identification and use of "barriers" to alter otherwise linear interpolation schemes, and thereby, permit the "mimicking" of those features. In the present case, barriers were used to identify and model the effects of islands, elevated roads, high dunes and bluffs, and canal berms. The following is a description of the approach used to develop improved maps of the storm-tide inundation resulting from Hurricane Rita.

The first step (1) in developing an improved storm-tide map is to select appropriate storm-tide data from the sensors. For Hurricane Rita, data from the sensors were reviewed and selected based on the appearance of the water-level hydrograph and patterns of data collected at other, nearby sites. Storm-tide waters penetrated inland at different rates throughout the study area. Some water-level sensors reported minimum (starting) water levels that were unrelated to the onset of storm tide. For example, at sites LC2a, LC2b, LA7 and LA8 (fig. 1), water-level sensors still recorded their starting elevations at 0300 hours on September 24, indicating that storm-tide waters had not yet arrived even though other sensors nearer to the coast were deeply flooded at that time. These data were not used to construct storm-tide elevation maps during the early phases of flooding.

Several sensors reported water levels that were the result of other processes, such as inland flooding. These situations were revealed by examination of the data with respect to the overall timing of landfall and available rainfall records. Sensors LA2 and LA3, for example, experienced flooding before Hurricane Rita made landfall because of locally intense rains. These data also were not used.

The second step (2) involves creating an approximate storm-tide surface using the spline method with a high tension (Smith and Wessel, 1990; Mitasova and Hofierka, 1993). Tension controls the stiffness of the interpolated surface. "Low-tension" spline fits can match recorded data at collection sites and still "drift" far above or below reasonable water-level elevations at locations between sensor sites. Higher tension causes the interpolated surface to be flatter and helps to avoid wild extrapolations especially at the edges of the study area. Tension values of about 20 were used to develop the interpolated surfaces for Hurricane Rita.

The third step (3) involves estimating the extent of the inundated area (boundary of flooding) from the interpolated surface created in step 2. Land surface based on the 30-meter-resolution digital elevation model (DEM) (http://seamless.usgs.gov/) was subtracted from the storm-tide surface resulting in areas of positive and negative values. Positive values represent the depth of storm tide; negative values represent dry land. The depth of storm tide was then contoured. Contours that are negative and closed indicate the presence of islands, dikes, canal berms, elevated roadbeds, etc. and were crucial to subsequent mapping and were saved for later analysis. Contours that are negative and open indicated uplands that were not flooded and were subsequently deleted. The most important contour resulting from this process was the zero-value ( 0 ) contour. This contour represented a line defining the extent of storm-tide inundation for the data associated with the time period.

The fourth step (4) involves identifying significant hydraulic barriers. The negative valued, closed contours that were saved in step 3 were overlain on orthophoto and quadrangle maps to identify islands, roads, berms, dunes, etc. that were higher than the storm-tide elevation and obstructed the inflowing storm tide. Just as important, breaks in topographic features such as bridges and stream crossings were manually identified, digitized, and included as breaks in the barriers. 
The fifth step (5) involves converting the zero contour line into data points having a zero storm-tide elevation. These points aided in improving the interpolation of storm tide near the boundary of flooding and were created at intervals of 15 to 30 kilometers along the zero contour line. After these points were created, they were relocated seaward about $1 \frac{1}{2}$ grid lengths (45 meter) of the DEM. The relocation was needed to ensure that the points were within the interpolation grid and would not be excluded from the final interpolation process.

The sixth step (6) involves use of the 'spline with barrier' interpolation method (Terzopoulos, 1988) to create a re-interpolated storm-tide elevation map. This re-interpolation utilized the original water-level data, the artificial points of zero elevation created in step 5, and the hydraulic barriers identified in step 4. In general, the barriers altered the lines of interpolation between two data points so that the interpolation lines went around the barrier rather than across it. After interpolation, the final surface was cleaned up by deleting surface values that were outside of the study area. The final surface can be used to develop contour and flood-depth maps and estimates of flood volumes and surface areas.

\section{HURRICANE RITA MAPPING APPLICATION}

A library of storm-tide maps of Hurricane Rita were developed using the improved mapping method. Maps were developed for the maximum surge and at 3-hour intervals for the period 0000 through 1200 on September 24, 2005. A map of the maximum storm tide was developed so that comparisons can be made to flood-inundation boundaries and to HWM data

\subsection{Maximum Storm Tide}

The maximum water level that was recorded anytime during or after Hurricane Rita at 19 water-level sensors (step 1 of the barrier mapping method) was used to create a map of maximum storm-tide elevations. The resulting map, shown in figure 2 shows that maximum storm-tide elevations (water-level elevations) were greatest along the coast and decreased inland. Maximum storm-tide elevation exceeded 15 feet at Rutherford's Beach, about 48 miles east of Sabine Pass, Texas, and about 15 feet at Constance Beach, Louisiana, approximately 20 miles east of Sabine Pass, Texas. The concavity of the coast in this area may have concentrated shoreward moving surge currents and resulted in high stormtide levels.

At its maximum, the storm tide extended north of the City of Lake Charles (LC2b) in and around the Calcasieu River, as much as 50 miles inland. The direct connection of the Calcasieu River and the expansive open waters composing Calcasieu Lake north of the coast contributed to maximizing the reach of the storm tide, and the narrowing of the Calcasieu River near the City of Lake Charles contributed to high storm-tide levels. The propagation of the storm tides up through other rivers and streams (the Mermentau River, Vermilion River, etc.), although extensive, probably was not as great as in the Calcasieu. Maximum penetration or extent of storm tide ranged from 50 miles to a minimum of about 25 miles (fig. 2).

The boundaries defining the extent of storm-tide inundation (step 3 of the barrier mapping method) were compared to the boundaries of the extent of flood-inundation maps produced by FEMA (fig. 2). Generally, these boundaries compared quite well especially along the Calcasieu River. Significant differences in boundaries near the City of Port Arthur are attributed to use by FEMA of jurisdictional boundaries to curtail mapping coverage and not to differences in data interpretations or mapping techniques. Differences north of Grand Lake and south of Interstate-10 are similarly explained that the FEMA boundary followed several Parish boundaries through the middle of Lake Arthur, Mermentau River, and unnamed creeks and canals. The FEMA boundary northeast of Grand Lake and Lake Arthur is straight edged and again followed Parish boundaries.

To develop flood-inundation maps resulting from Hurricane Rita, FEMA identified and surveyed the elevations of more than 350 HWMs in southern Louisiana (USR Group, Inc., 2006). Only HWMs that were 
identified as having been caused by "storm surge" are shown in figure 2. The elevations of HWMs varied substantially, even those located in close proximity to one another. Such differences are attributable to the difficultv of ohtainina reliable stable HWMs in areas that exnerienced considerable wave action and

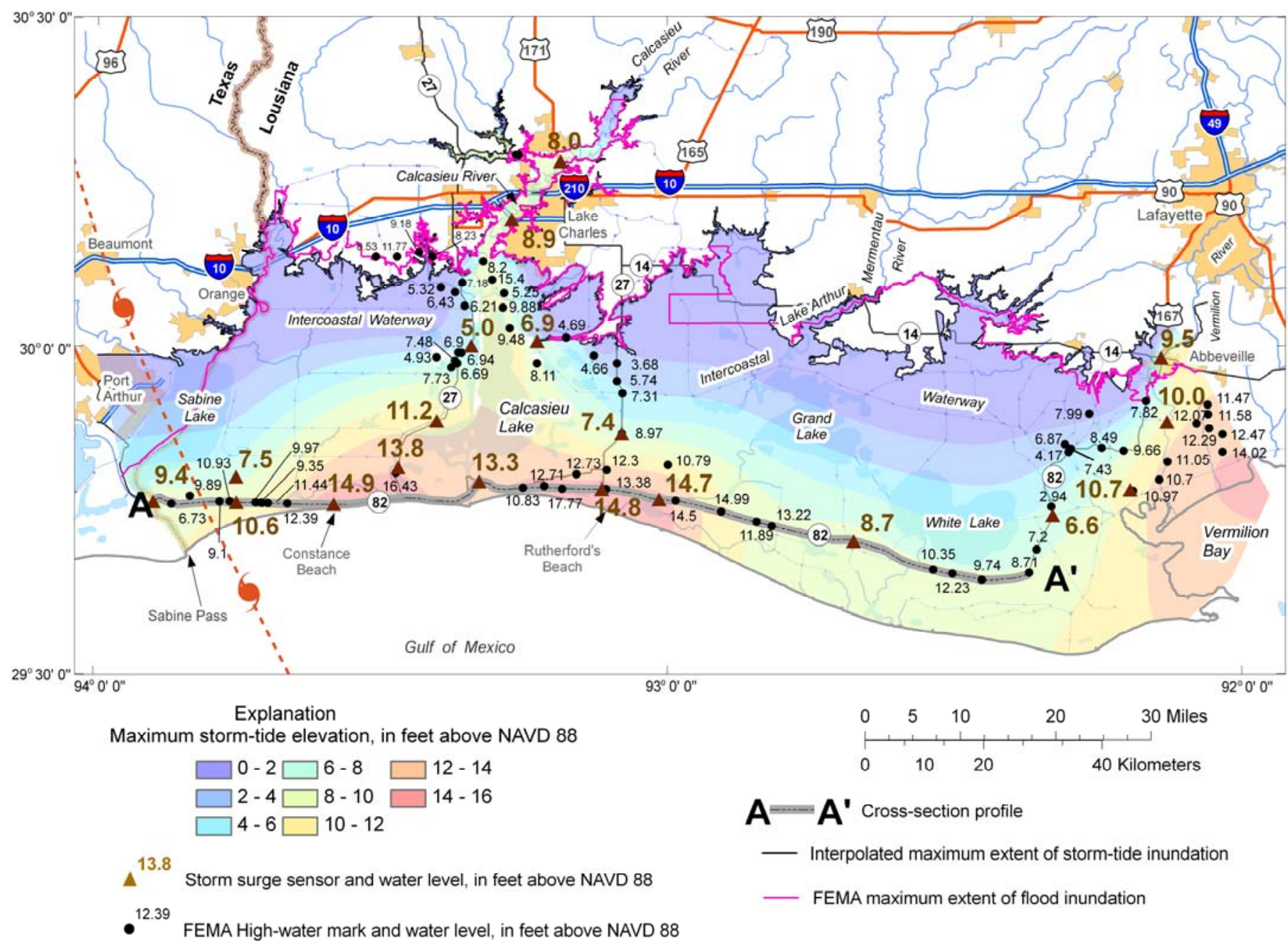

Figure 2. Map showing maximum storm-tide elevation using the barrier mapping method, maximum extent of inundation, maximum storm-tide elevation at sensors, and FEMA high-water mark elevations.

A cross-section profile (A-A') that parallels the Louisiana coast on State Road 82 was developed (fig. 3) from the maximum storm-tide elevation map. Differences between the elevations of HWMs and the stormtide map are evident, but overall, the trend of the HWMs generally reflects those of the mapped storm-tide surface for most of the length of profile A-A'. However, the HWMs located along the eastern (most rightward) section of the profile were substantially higher than storm-tide elevations derived from the map. The maximum water level located at sensor LA10 (8.7 feet) might be unreliable, but the operation of other sensors throughout the study area were confirmed to be working properly and measuring accurately as indicated by McGee and others (2006a, 2006b). At nearby sensor LA9, for example, water levels from tape downs (which involved measuring the distance from a reference mark of known elevation to the water surface at the sensor) agreed closely (within 0.1 foot) with the recorded water-level data (McGee and others, 2006a). The maximum water level at sensor LA9 was 6.6 feet, which is much lower than nearby FEMA HWMs and is consistent with water level and HWMs comparisons at LA10. 


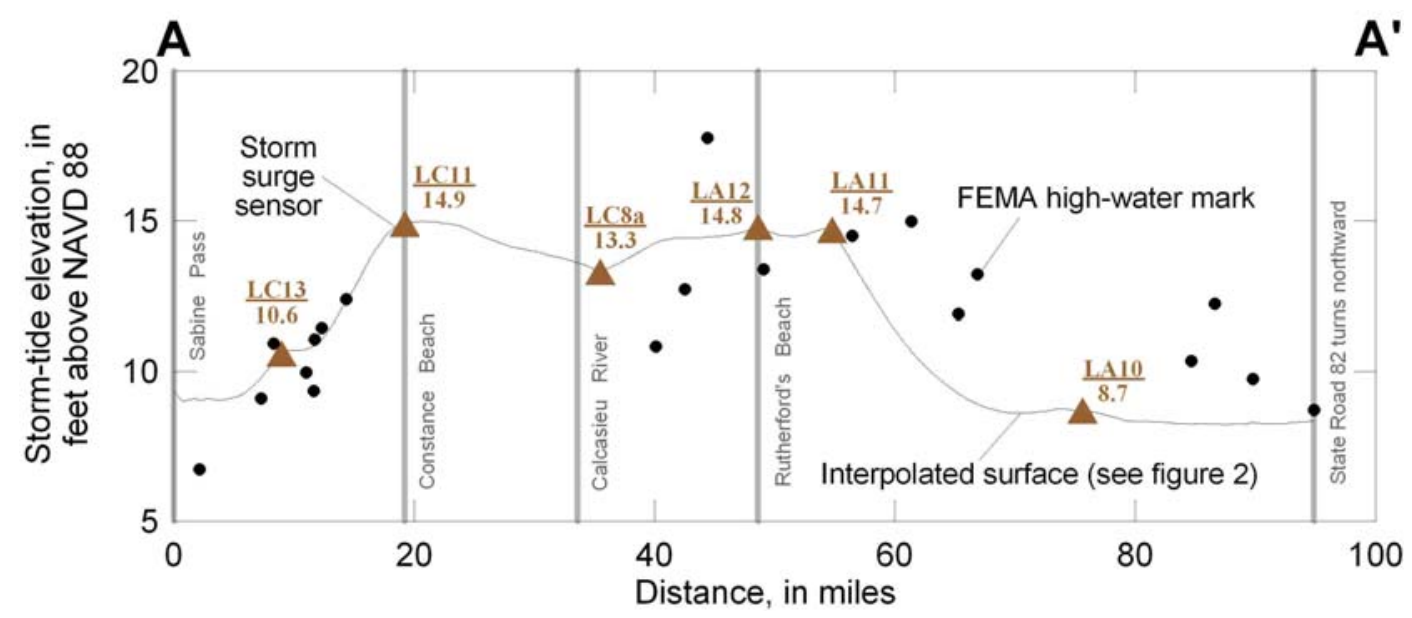

Figure 3. Cross-section profile $A-A^{\prime}$ along the Louisiana coast showing the maximum storm-tide interpolated surface and USGS sensors and FEMA high-water marks.

\subsection{Other Storm-Tide Periods}

The barrier mapping method was also applied to the storm-tide data at 3-hour intervals from midnight (0000 hours) through noon (1200 hours) on September 24, 2005 (fig. 4). The resulting storm-tide surfaces (fig. 4) clearly indicate the influences of coastal orientation with respect to the hurricane path and relative elevations of steams, marshes, roads, and uplands, especially in early sequences before many of these features where overtopped as the storm tide increased. By 0000 hours (fig. 4a), the storm tide had penetrated marshlands in the southwest, near the mouth of the Calcasieu River, and east of State Road 82 where it heads northeastward. Elevations had reached 10 to 12 feet along the eastern marsh and 14 feet near the Calcasieu River (fig. 4a). The hydraulic interference of State Road 82 is clearly evident. The road acted as a leaky dam, however, and resisted inland flow except at locations where bridges or culverts permitted conveyance. This damming effect was evident along State Road 82 to its junction with State Road 14. Berms along the northwestern reach of the Intercoastal Waterway also severed as a dam and resisted storm-tide flows from the south. Several high bluffs, along the shores of Lake Charles remained above storm-tide levels.

At 0300 hours (fig. 4b), the storm tide had peaked along the coast. Water level from the storm tide exceeded 15 feet at Rutherford's Beach. All but the most northern extent of State Roads 82 and 14 were under water. The influence of the Calcasieu River is evident as the storm tide penetrated more quickly along its length than elsewhere. Several high bluffs on the western shore of the lake remained above the storm tide. The Intercoastal Waterway west of the City of Lake Charles continued to stall northward flows.

By 0600 hours (fig. 4c), storm-tide elevations at the coast were much diminished and rarely exceeded 10 feet. At 0900 hours (fig. 4d), the highest storm-tide surface moved northward and inland and centered over LC7, about 9 miles inland from the coast. By this time, the storm tide at Rutherford and Constance Beaches declined to about 7.5 feet. By 1200 hours (fig. 4e), the highest storm-tide surface moved northward along the Calcasieu River to the City of Lake Charles near sensors LC2a and LC2b. The area north of the Intercoastal Waterway and west of the City of Lake Charles was probably flooded by stormtide waters going around the northern berm of the Intercoastal Waterway at the Calcasieu River. During steps 3 and 4 of the mapping barrier method, several areas along the berms in this area were partially overtopped, and only the non-overtopped (dry areas) berms were used as barriers to flow in step 6 . Light 
Detection and Ranging (LIDAR) data of the area are needed to make a more accurate determination as to dry and overtopped (flooded) berms.

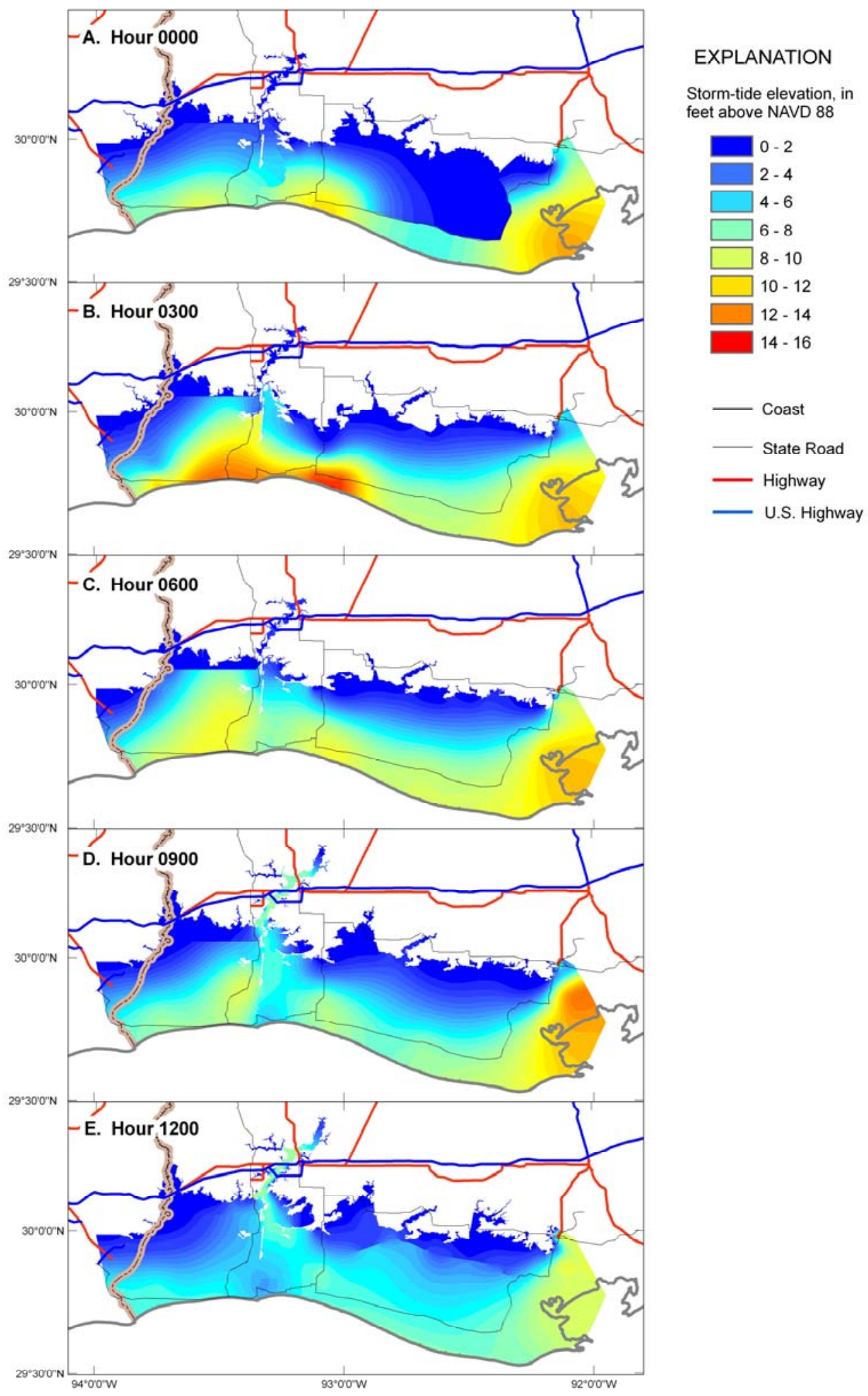


Figure 4. Interpolated storm-tide elevations using the barrier mapping method at 3-hour intervals from midnight (0000 hours) through noon (1200 hours), September 24, 2005, Hurricane Rita.

\section{CONCLUSIONS}

No map is better than the data used to construct it and the maps presented are but one depiction of the storm-tide elevations that may have existed during Hurricane Rita. USGS crews placed the sensors in an opportunistic fashion, taking advantage of road access and the presence of structures on which to locate the sensors. Obviously, if the sensors had been located elsewhere within the storm-tide area, the interpolation process may have yielded elevations of varying degrees of similarity to those shown in figures 2 and 4 . Regardless, the use of the barrier mapping method links the water-level dataset to major topographic and hydraulic features, improves the depiction of the storm tide though time and space, and promotes depictions that are more realistic, consistent, and robust than those resulting from direct interpolations.

The barrier mapping method is not a substitute for a properly calibrated and data-driven hydrodynamicstorm-surge model. Such models could produce more accurate and robust flood maps. But the input data needed for such a model are often difficult to obtain, especially during or immediately after a storm. In these situations, a map derived from a simple and easy GIS process may be the best practical solution.

\section{REFERENCES}

McGee, B.D., Goree, B.B., Tollett, R.W., Woodward, B.K., and Kress, W.H., 2006a. Hurricane Rita Surge Data, Southwestern Louisiana and Southeastern Texas, September to November 2005. U.S. Geological Survey Data Series 220. http://pubs.usgs.gov/ds/2006/220/ (accessed 1/2/2008).

McGee, B.D., Tollet, R. W., and Mason, R.R., Jr. 2006b. Monitoring inland storm surge and flooding from Hurricane Rita. U.S. Geological Survey Factsheet 2006-3136. http://pubs.usgs.gov/fs/2006/3136/pdf/fs2006-3136.pdf (accessed 1/2/2008)

Mitasova, Helena, and Hofierka, Jaroslav. 1993. Interpolation by regularized spline with tension-II. Application to terrain modeling and surface geometry analysis. Mathematical Geology, v. 25, n. 6, 657-669.

Smith, W.H.F., and Wessel, P. 1990. Gridding with continuous curvature splines in tension. Geophysics, v. 55, n. 3, March, 293-305.

Terzopoulos, D. 1988. The computation of visible-surface representations. Institute of Electrical and Electronics Engineers Transactions on Pattern Analysis and Machine Intelligence, v. 10, n. 4, July, 417-438.

URS Group, Inc. 2006. Hurricane Rita Rapid Response-Louisiana Coastal \& Riverine High Water Mark Collection. Final report submitted to FEMA, Contract No. EMW-2000-CO-0247, URS Group, Inc., 200 Orchard Ridge Drive, Suite 101, Gaithersburg, MD 20878, [79]. http://www.fema.gov/pdf/hazard/flood/recoverydata/rita/rita la hwm public.pdf (accessed 1/2/2008) 